M. D. Dominic Bell

\title{
Early identification of the potential organ donor: fundamental role of intensive care or conflict of interest?
}

Received: 21 April 2010

Accepted: 24 April 2010

Published online: 3 June 2010

(C) Copyright jointly held by Springer and ESICM 2010

M. D. D. Bell (必)

Department of Intensive Care/Anaesthesia,

The General Infirmary at Leeds,

Great George Street, Leeds LS1 3EX, UK

e-mail: dominic.bell@leedsth.nhs.uk

Tel.: +44-113-2432799

Fax: +44-113-3922645

Intensive care and cadaveric organ donation have been inextricably linked since the opportunity inherent in profound neurological injury was realised and the concept of brain death created [1]. Despite initial unease [2], the objectivity of the testing procedure and acknowledgement of the condition as an end-point for futility, even if not the diagnosis of death, were key to virtually universal acceptance of brain/brainstem death as a platform for donation. As transplantation evolved, however, from experimental to mainstream treatment, demand inevitably grew, creating new pressures on critical care. Potential solutions to the shortage have included 'marginal donors' [3], and more contentious initiatives such as 'elective ventilation' [4] and non-heart-beating organ donation (NHBD) [5]. The limited uptake of the latter reflects uncertainty as to ethical and legal defensibility [6], and additional recruitment strategies have highlighted escalating conflict of interest.

Trained 'facilitators' to address high rates of relatives' refusal have been criticised for possible coercion [7], and 'embedded coordinators' to ensure early identification of potential donors [8] indicate a pressure which warrants reflection. The argument that intensivists are not doing enough to maximise donor numbers as justification for the above initiatives, if accurate, would demonstrate differences in prioritisation which need exploring, and if inaccurate, displays at best an insensitivity to the need to maintain the support of the critical care community.

Against this background, how should the article on identifying 'imminent brain death' in this month's journal by de Groot and colleagues from multiple disciplines, primarily from the Netherlands, be evaluated [9]?

The declared intention to increase the conversion rate from potential to actual donors would be a positive response to the above criticisms by transplantation services. The proposed mechanism of an objective assessment for early identification of the beating-heart donor should resonate with the needs of intensivists to minimise protracted futile care, and by such objectivity, avoid concern that decisions are taken for utilitarian advantage.

This proposal would therefore benefit all parties and demonstrate a welcome compatibility of principles between intensive care and transplantation services. The key question is whether the proposition has the objectivity and applicability that the authors envisaged.

Brain injury is so heterogeneous among and within the principal mechanisms of trauma, vascular event, infection and hypoxia that the level of function assessed by GCS (Glasgow Coma Score) on presentation is rarely used to determine whether active intervention should be pursued. Given the emphasis on avoiding secondary cerebral insults, analgesia, sedation and often muscle paralysis are administered to optimise gas exchange and stabilise the patient, whilst monitoring parameters such as intracranial pressure (ICP) to assess the magnitude of the primary injury. Derangement of these measurements is usually the prelude to escalation of therapy or additional interventions such as barbiturates, hypothermia or decompressive craniectomy [10].

In this scenario, given that otherwise objective investigations such as CT cannot define prognosis except in 
extreme circumstances such as bilateral hemispheric infarction or herniation, the need for alternative options to rationalise continuation or cessation of active care is recognised.

It is uncertain, however, in the usual context of intense support and intervention as described, how either the GCS or clinical tests of brainstem function would be validated. There is an inherent danger that in stopping therapies which are potentially optimising the patient, to validate a testing procedure, that progression to brainstem death will occur as a consequence of this strategy, a criticism previously directed at the apnoea test [11]. Furthermore, if the described observations are made after stopping all interventions to undertake a valid clinical assessment, it is predictable that the patient will have survived long enough after the primary injury to make progression to brain/brainstem death less likely. It is unclear therefore as to which mechanism of brain injury, at what timing, and after which therapy or intervention the authors consider this clinical assessment valid for prognosis, change in management, and benchmarking of individual units on donor conversion rates.

A proportion of patients, despite all treatment options, declare progression towards brain/brain stem death by developing dilated unreactive pupils accompanied by cardiovascular instability and occasionally diabetes insipidus, thereby justifying cessation of sedation and ICP-directed therapy and management of the patient with formal testing in mind. The challenge with the remaining majority lies in deciding whether to continue with active support, stop all life-sustaining measures with the inevitability of death and potential NHBD, or to stop sedation but continue support with the intention of making a functional clinical assessment once sedation is cleared. By virtue of the treatment delivered up until this point, the proposed clinical assessment and FOUR score would be invalid for this decision in any of the above categories of patients.

Objectivity and applicability appear vulnerable therefore, and the tool is correspondingly weak when considering the authors' additional goal of evaluation of an individual unit's performance in identifying and converting potential organ donors. The challenge that is created by the authors' initiative is to review scenarios where objective testing would assist decision-making about futility and then refine that process to a level where professional and public confidence would support routine deployment and to reasonably allow inter-unit comparisons.

Most neurosurgical units would recognise that aggressive medical and surgical intervention for raised ICP has been associated with overall reduction in numbers progressing to brain/brainstem death, and that treatment, either through the residual effects of sedation or metabolic disturbance, has delayed or invalidated clinical testing when brainstem death is strongly suspected on clinical grounds, leading to lost donation opportunities. In these circumstances, whilst NHBD would remain an option, objective testing such as angiography or CT perfusion studies [12] could consolidate the clinical diagnosis of brain/brainstem death without delay whilst awaiting drug clearance, etc. Additional work is also required with cerebral Doppler [13] and brainstem evoked potentials [14] before these tools achieve universal acceptance for equivalence with direct vascular studies, but utilisation of bedside technology would have certain practical advantages.

With an acknowledged shift away from brainstem death, the greatest challenge lies, however, in identifying futility as a prelude to withdrawal of active support and potential NHBD in the cohort of patients in whom sedation has been stopped to make a functional neurological assessment. There is unfortunately no database which maps prognosis against for example extensor posturing in a 16-year-old patient 2 days after weaning from sedation following a diffuse axonal injury, and most practitioners will recognise that there is significant variation in the management of such patients. Given that these groups greatly outnumber the target population of de Groot and colleagues, that the socio-economic consequences of survival with profound disability are significant, and that high numbers of potential donors via NHBD are predictably lost, it would appear that attention could be more appropriately directed on this population. It is noteworthy that whilst features of neurological disability after hypoxic brain injury have been strongly identified as carrying a sufficiently poor prognosis to justify withdrawal of active support [15], there is little evidence of objectivity and consistency for other mechanisms of brain injury.

This paper therefore undoubtedly highlights a need for objectivity in deciding whether to initiate, maintain, escalate or withdraw active support at various key stages after neurological injury, and for consistency in uptake and implementation. Despite the reservations, de Groot and colleagues have started the dialogue, which is essential if professional and public confidence is to be maintained in primary decision-making. Without objectivity on futility, it is difficult to eliminate the perception of conflict-of-interest with regard to donor recruitment, and one can reasonably question the involvement of organ procurement organisations in the paper's proposals. At a time when the very concept of brain death remains under scrutiny [16], it is potentially hazardous to be considering changing the emphasis of care whereby the patient is treated as though they are dead with the goal of reaching that diagnosis, on the basis of a scoring system which has not been validated for that purpose, and by a process with the inherent risk of aggravating the underlying brain injury.

The primary goal of intensive care is to actively treat potentially reversible disease or injury, until such time 
as the goals are proven to be unachievable, rather than to process organ donors. Defining futility has to be both objective and divorced from organ donation in an

explicit manner if support for proposed withdrawal of Conflict of interest statement None. care as a prelude to any form of organ donation is to be realised.

\section{References}

1. [No authors listed] (1968) A definition of irreversible coma. Report of the Ad Hoc Committee of the Harvard Medical School to Examine the Definition of Brain Death JAMA 205:337-340

2. Hoffenberg R (2001) Christiaan Barnard: his first transplants and their impact on concepts of death. BMJ 323:1478-1480

3. Kuo PC, Lu AD, Johnson LB (2001) Expanded criteria donors/high risk recipients is not always cheaper than hemodialysis. Transplantation 72:554-555

4. Feest TG, Riad HN, Collins CH, Golby MG, Nicholls AJ, Hamad SN (1990) Protocol for increasing organ donation after cerebrovascular deaths in a district general hospital. Lancet 335:1133-1135

5. Koostra G, Daemon JHC, Oomen APA (1995) Categories of non-heart-beating donors. Transplant Proc 27:2893-2894

6. Bell MDD (2008) Non-heart beating organ donation - in urgent need of intensive care. Br J Anaesth 100:738-741

7. Truog RD (2008) Consent for organ donation-balancing conflicting ethical obligations. N Engl J Med 358:1209-1211
8. Department of Health (2008) Organs for transplants: a report from the Organ Donation Taskforce. Department of Health, London

9. de Groot YJ, Jansen NE, Bakker J, Kuiper MA, Aerdts S, Maas AIR, Wijdicks EFM, van Leiden HA, Hoitsma AJ, Kremer B (HPH), Kompanje EJO (2010) Imminent brain death: point of departure for potential heart-beating organ donor recognition. Intensive Care Med. doi: 10.1007/s00134-010-1848-y

10. Guerra WK, Gaab MR, Dietz H, Mueller JU, Piek J, Fritsch MJ (1999) Surgical decompression for traumatic brain swelling: indications and results. J Neurosurg 90:187-196

11. Coimbra CG (1999) Implications of ischemic penumbra for the diagnosis of brain death. Braz J Med Biol Res 32:1479-1487

12. Frampas E, Videcoq M, de Kerviler E, Ricolfi F, Kuoch V, Mourey F, Tenaillon A, Dupas B (2009) CT angiography for brain death diagnosis. Am J Neuroradiol 30:1566-1570

13. Research Group of the World Federation of Neurology (1998) Consensus opinion on diagnosis of cerebral circulatory arrest using Doppler-sonography: Task Force Group on Cerebral Death of the Neurosonology Research Group of the World Federation of Neurology. J Neurol Sci 159:145-150
14. Sonoo M, Tsai-Shozawa Y, Aoki M Nakatani T, Hatanaka Y, Mochizuki A, Sawada M, Kobayashi K, Shimizu T (1999) N18 in median somatosensory evoked potentials: a new indicator of medullary function useful for the diagnosis of brain death. J Neurol Neurosurg Psychiatry 67:374-378

15. Wijdicks EFM, Parisi JE, Sharbrough FW (2004) Prognostic value of myoclonus status in comatose survivors of cardiac arrest. Ann Neurol 35:239-243

16. Engelhardt HT Jr (1999) Redefining death: the mirage of consensus. In: Youngner SJ, Arnold RM, Shapiro R (eds) The definition of death: contemporary controversies. John Hopkins University Press, Baltimore, pp 319-331 